\title{
The ameliorative potential of Hyphaene thebaica on streptozotocin-induced diabetic nephropathy
}

\author{
M. AbdEl-moniem ${ }^{1}$, H.N. Mustafa ${ }^{2}$, H.A. Megahed ${ }^{1}$, M.H. Agaibyi ${ }^{1}$, \\ G.A. Hegazy1,3, M.A. El-Dabaa ${ }^{4}$ \\ ${ }^{1}$ Medical Biochemistry Department, National Research Centre, Cairo, Egypt \\ ${ }^{2}$ Anatomy Department, Faculty of Medicine, King Abdulaziz University, Jeddah, Saudi Arabia \\ ${ }^{3}$ Clinical Biochemistry Department, Faculty of Medicine, King Abdulaziz University, Jeddah, Saudi Arabia \\ ${ }^{4}$ Botany Department, National Research Centre, Cairo, Egypt
}

[Received 6 January 2015; Accepted 23 February 2015]

\begin{abstract}
Background: Diabetic nephropathy (DN) is the leading cause of end-stage renal disease. The aim of the current study is to investigate the possible beneficial effects of Hyphaene thebaica in DN.

Materials and methods: For this, 50 male albino rats were divided into five groups: group I - represented the control group; group II - received Hyphaene thebaica extracts of $150 \mathrm{mg} / \mathrm{kg}$ BW by oral gavage for 6 weeks; group III - received single intraperitoneal injections of streptozotocin (50 mg/kg BW) to induce type-2 diabetes mellitus; group IV (protective) - diabetic rats received Hyphaene thebaica extract (150 mg/kg BW) orally for 6 weeks; group $V$ (curative) - received Hyphaene thebaica extract (150 mg/kg BW) orally after the diagnosis of DN.

Results: In the DN protected group, blood glucose, urea, and creatinine decreased significantly, while insulin and C-peptide increased significantly. Moreover, cystatin C and neutrophil gelatinase-associated lipocalin decreased. Collagen fibre deposition is increased with an apparent thickening of the parietal layer of Bowman's capsules and the basal lamina of convoluted tubules, as well as increase of the immune-reaction of caspase-3 and desmin. The introduction of Hyphaene thebaica led to greater amelioration in the biochemical markers, apoptotic alterations, and podocyte injuries of the protected group than in the curative group.

Conclusions: Hyphaene thebaica may be advised as a good choice that can delay diabetic renal complications. (Folia Morphol 2015; 74, 4: 447-457)
\end{abstract}

Key words: diabetic nephropathy, Hyphaene thebaica, podocyte injury, apoptosis

\section{INTRODUCTION}

Diabetes mellitus is one of the most common disease affecting the populations around the world. Roughly 285 million individuals are diabetic worldwide, and this number is expected to increase $54 \%$ by 2030 [42]. Diabetic nephropathy (DN), a renovascular complication that affects nearly $30 \%$ of diabetics and leads to an end-stage renal disease, is a common microvascular complication of type 2 diabetes mellitus [21]. The early diagnosis of DN is crucial to avoid the destructive outcomes of renal failure among diabetics [27]. While microalbuminuria has been recognised as a significant predictive marker for the early diagnosis of DN [27], some diabetics may develop DN without

Address for correspondence: Dr. Hasham N. Mustafa, Assistant Professor, Faculty of Medicine, King Abdulaziz University, P.O. Box 80205 Jeddah, 21589 Saudi Arabia, tel (office): +966 126400 000, ext. 22016, (mobile):+966 566764 762, (Egypt): +201 001460009 ,

e-mail: hmustafa@kau.edu.sa 
an apparent microalbuminuria [18]. Therefore, sensitive and specific markers are required to detect DN in its early stages [27].

Cystatin C (Cys C) is considered as an important marker for DN, which represent a preferable substitute for serum creatinine in the estimation of glomerular filtration rates, especially in evaluating the prognosis of chronic renal diseases [17]. Neutrophil gelatinase-associated lipocalin (NGAL) is a biomarker expressed in numerous human tissues, including the kidney, and is of significant expression within injured epithelia [39]. NGAL genes have been found to be strongly expressed following renal ischaemic or nephrotoxic injuries in animal models [36]. NGAL can be detected both in the blood and urine and has been considered to be an early predictor of acute kidney injury in various clinical disorders [32].

The World Health Organisation has encouraged research on medicinal plants as antidiabetics [1,37]. Hyphaene thebaica is an African palm tree common in Upper Egypt [3], the fruit contains significant amounts of saponins, coumarins, hydroxycinnamates, essential oils, flavonoids, alkaloids, reducing sugars, glycosides, and water-soluble phenolic contents with powerful antioxidant activity [15].

The fruit of the Hyphaene thebaica, known as a famine food, is considered a life-sustaining nutrient in desert areas, especially during periods of drought [15]. The plant is known to possess phytochemical constituents with antidiabetic capacities [1]. Phenolics and oxylipids within the plant were determined using UPLC-PDA-TOF (ultra-performance-photodiode array-time of flight) high-resolution mass spectrometry in order to obtain their molecular formula and their exact mass under-optimised conditions. Seventeen compounds were identified and quantified from the fruit of Hyphaene thebaica, including 2 cinnamic acid derivatives, 5 flavonoids, 6 fatty acids, 2 sphingolipids, a lignan, and a stilbene. The plant's sugar composition was characterised and quantified by $1 \mathrm{H}$-nuclear magnetic resonance, with sucrose detected as its major component at a level of $219 \mathrm{mg} / \mathrm{g}$ [3].

Hyphaene thebaica has an antioxidant activity due to the substantial amount of water-soluble phenolic contents of flavonoids within it. These contents represent conjugates of o-glycosides, which include quercetin, chrysoeriol, luteolin, and isorhamnetin $\mathrm{H}$ $[1,15]$. Moreover, Hyphaene thebaica is known to possess anti-inflammatory capacities due to its ability to inhibit cyclooxygenase (COX-1), an enzyme known to be involved in the inflammation [37]. Therefore, the present work aims to study the protective and curative effects of Hyphaene thebaica extract on induced DN.

\section{MATERIALS AND METHODS}

Plant material. The Hyphaene thebaica (doum) fruit was obtained from local markets in Giza, Egypt.

Preparation of extracts. The fruits was cleaned and separated into pulp. The pulp was then dried and ground into powder, which was sieved through a $0.25 \mathrm{~mm}$ sieve (Endecott Test Sieves Ltd., London, UK). Subsequently, $50 \mathrm{~g}$ of the powder was extracted and treated with $100 \mathrm{~mL}$ of ethyl alcohol overnight. In order to obtain the dried extracts, the solvents were left to evaporate spontaneously. Aqueous suspension was performed by suspending $50 \mathrm{~g}$ of the powdered pulp in $100 \mathrm{~mL}$ of distilled water and stored at a low temperature. The suspension was then shaken vigorously to obtain a homogenous mixture before the oral administration of Hyphaene thebaica extracts [1].

Animals. Adult male albino rats of the Sprague-Dawley strain weighing 175-210 g were obtained from the animal house of the National Research Centre (NRC) in Giza, Egypt. The rats were housed individually in stainless steel cages at $22 \pm 2^{\circ} \mathrm{C}$ under a light/dark cycle and allowed to acclimatise for a period of 7 days before the experiment with free access to food and water ad labium. All work followed the recommendations of the National Institute's Guide for the Care and Use of Laboratory Animals and was approved by the Animal Ethical Committee of the NRC in Cairo, Egypt.

Induction of type 2 diabetes mellitus. Diabetes was induced in fasted rats overnight via intraperitoneal single injections of freshly prepared streptozotocin

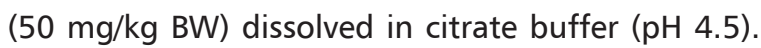
Rats were considered diabetic if their fasting blood sugar measured after $72 \mathrm{~h}$ exceeded $250 \mathrm{mg} / \mathrm{dL}$ [46].

Experimental design. 50 rats were divided into the following five groups of ten rats each:

- group I (the control group): received $0.1 \mathrm{M}$ citrate buffer $\mathrm{pH}$ (4.5) for 6 weeks [29];

- group II: received Hyphaene thebaica extract $150 \mathrm{mg} / \mathrm{kg}$ BW by oral gavage for 6 weeks [1];

- group III (DN group): included diabetic nephropathy without treatment;

- group IV (prophylactic group): diabetic rats received the same dose of Hyphaene thebaica extract orally for 6 weeks immediately after being 
diagnosed as diabetic as a protective against the consequences of diabetes, including nephropathy;

- group V (curative group): diabetic rats received the same dose of Hyphaene thebaica orally for 3 weeks upon being diagnosed with nephropathy at the 4th week $[6,40]$.

Sample collection. At the end of experiment, blood samples were collected from the retro-orbital plexuses of veins using capillary tubes. The samples were centrifuged at $3000 \mathrm{rpm}$ for $15 \mathrm{~min}$ to separate the serum. The serum was then frozen at $-20^{\circ} \mathrm{C}$ for the subsequent estimation of biochemical parameters.

Analysis of biochemical indices. Serum glucose levels were measured using enzymatic colorimetric methods with commercial kits (Randox Laboratories, Ltd., Antrim, UK). Serum urea and creatinine levels were assayed spectrophotometrically according to standard procedures using commercial diagnostic kits supplied by the Biodiagnostic Company (Cairo, Egypt). Serum insulin levels were determined by enzyme-linked immunosorbent assay (ELISA) using the Boehringer-Mannheim kit with a Boehringer model ES300 analyser (Boehringer, Germany). Serum C-peptide levels were determined using a quantitative solid-phase ELISA using kits from the Immunospec Co., USA. Serum Cys C and serum NGAL were determined quantitatively using ELISA kits supplied from Glory Science Co., USA.

Histological study. The rats were sacrificed by decapitation and renal samples were preserved in $10 \%$ neutral buffered formalin. Samples of $5 \mu \mathrm{m}$ thickness were prepared and stained with Haematoxylin and Eosin (H\&E) for routine exam and with Masson's Trichrome to visualise the collagen fibres. Then observed using an Olympus BX53 microscope equipped with a DP73 camera (Olympus, Tokyo, Japan) [28, 41].

Immunohistochemical study. The renal samples were immunostained using primary antibodies caspase-3 (a marker for apoptosis; rabbit polyclonal, Cat. no. 250573, Abbiotec-San Diego, USA; dilution 1: 200) and desmin (a marker for podocyte injury; monoclonal mouse antibody, Lab Vision Corp, NeoMarkers Inc/Lab Vision, Fremont, California, USA; dilution 1: 100) according to the manufacturers' guidelines. The avidin-biotin complex peroxidase method was used for the immunohistochemical study. Sections were incubated for $20 \mathrm{~min}$ in DAB chromogen (3,30 diaminobenzidine) and then counter-stained with Mayer's haematoxylin. For positive control sections, standard laboratory slides were used for all stains to validate the success of the immunohistochemical technique. All slides were examined under light microscopy and the presence of labelled cells was documented. The absence of staining was recognised as a negative result, while the presence of brown staining was recognised as a positive result [16].

Morphometrical analysis. 20 non-overlapping fields from the ten rats in each experimental group were randomly selected. Renal parameters were analysed in terms of the diameter of the renal corpuscle and urinary space (of nearly round sections) using the Image-Pro Plus v6.0 (Media Cybernetics, Maryland, USA) and ImageJ software v1.49n (NIH) to confirm the analysis outcomes. Furthermore, the mean percentage area of positive immune cells was calculated and analysed for comparison with the control group [16].

Statistical analysis. The data analysis was carried out using the Statistical Package of Social Science software version 22 (SPSS Inc., Chicago, IL, USA). All numeric variables were expressed as mean \pm standard deviations (SD). Statistical comparisons were performed using one-way analysis of variance (ANOVA) tests followed by post-hoc least significant difference for multi-group comparisons. The homogeneity of variance was assessed using Levene's test. Differences were considered significant if $p<0.05$ [28].

\section{RESULTS}

The results of this study showed the significant elevation of glucose, urea, and creatinine serum levels in the untreated DN, prophylactic, and curative groups compared with the control and control Hyphaene thebaica groups. Treatment with Hyphaene thebaica in the prophylactic and curative groups induced a significant decrease in the serum levels of glucose, urea, and creatinine compared with the untreated DN group. However, these levels in the latter were still significantly higher than those of the control and control Hyphaene thebaica groups. Moreover, a significant decrease was found in the serum levels of glucose, urea, and creatinine in the prophylactic group compared with the curative group (Table 1, Fig. 1).

In the DN, prophylactic, and curative groups, serum levels of insulin and C-peptide were found to be significantly decreased, and serum levels of Cys C and NGAL were found to be significantly increased compared with the control and control doum groups. In the prophylactic and curative groups, the serum levels of insulin and C-peptide were found to be significantly increased, and 
Table 1. Comparison of blood glucose and serum levels of urea and creatinine in different studied groups

\begin{tabular}{|c|c|c|c|c|c|}
\hline Parameters & Control group & Control doum group & DN group & Prophylactic group & Curative group \\
\hline \multirow[t]{5}{*}{ Serum glucose [mg/dL] } & $96.00 \pm 13.08$ & $95.00 \pm 10.54$ & $250.00 \pm 37.71$ & $150.00 \pm 18.86$ & $188.00 \pm 47.80$ \\
\hline & & & ${ }^{1} p<0.0001$ & ${ }^{1} p<0.0001$ & ${ }^{1} p<0.0001$ \\
\hline & & & ${ }^{2} p<0.0001$ & ${ }^{2} p<0.0001$ & ${ }^{2} p<0.0001$ \\
\hline & & & & ${ }^{3} p<0.0001$ & ${ }^{3} p<0.0001$ \\
\hline & & & & & ${ }^{4} p<0.006$ \\
\hline \multirow[t]{5}{*}{ Serum urea [mg/dL] } & $14.19 \pm 5.15$ & $15.25 \pm 4.65$ & $77.40 \pm 11.45$ & $48.33 \pm 9.49$ & $69.33 \pm 4.58$ \\
\hline & & & ${ }^{1} p<0.0001$ & ${ }^{1} p<0.0001$ & ${ }^{1} p<0.0001$ \\
\hline & & & ${ }^{2} p<0.0001$ & ${ }^{2} p<0.0001$ & ${ }^{2} p<0.0001$ \\
\hline & & & & ${ }^{3} p<0.0001$ & ${ }^{3} p<0.022$ \\
\hline & & & & & ${ }^{4} p<0.0001$ \\
\hline \multirow[t]{5}{*}{ Serum creatinine $[\mathrm{mg} / \mathrm{dL}]$} & $1.14 \pm 0.33$ & $1.31 \pm 0.30$ & $6.61 \pm 1.87$ & $3.01 \pm 1.02$ & $5.00 \pm 1.35$ \\
\hline & & & ${ }^{1} p<0.0001$ & ${ }^{1} p<0.032$ & ${ }^{1} p<0.0001$ \\
\hline & & & ${ }^{2} p<0.0001$ & ${ }^{2} p<0.050$ & ${ }^{2} p<0.0001$ \\
\hline & & & & ${ }^{3} p<0.0001$ & ${ }^{3} p<0.0003$ \\
\hline & & & & & ${ }^{4} p<0.0001$ \\
\hline
\end{tabular}

Values are presented as mean \pm standard deviation; ${ }^{1} p$ - significance vs. control group; ${ }^{2} p-$ significance vs. control doum group; ${ }^{3} p$ - significance vs. diabetic nephropathy (DN) group; ${ }^{4} \mathrm{p}$ - significance vs. prophylactic group; $\mathrm{N}=10$ for each group

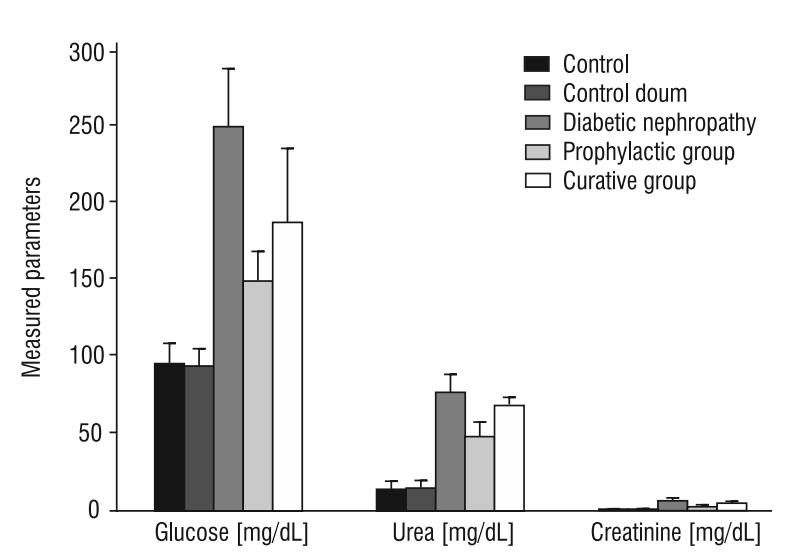

Figure 1. Comparison of blood glucose and serum levels of urea and creatinine in different studied groups.

the serum levels of Cys C and NGAL were found to be significantly decreased compared with the DN group. Moreover, a significant increase in the serum levels of insulin and C-peptide in the prophylactic group, and a significant decrease in the serum levels of Cys $C$ and NGAL were found compared with the curative group (Table 2, Fig. 2).

Histological results. The regular histological architecture was demonstrated in the control group and the group treated with Hyphaene thebaica only (Fig. 3A). The DN group showed varying degrees of deterioration in the histological architecture, with apparently increased glomeruli sizes, including congested capillary vessels, vacuolar degeneration of the tubules, hyaline casts, and certain tubules with distorted cellular boundaries and areas of extravasated blood cells (Fig. 3B). The group protected from DN by Hyphaene thebaica revealed nearly normal renal architectures and minimal alterations, no hyaline casts, no extravasated blood cells, and reduction of glomerular congestion (Fig. 3C). DN treated with Hyphaene thebaica displayed no observable improvement in the histological alterations of the glomeruli and tubules (Fig. 3D). The results showed a significant elevation of renal corpuscle diameters in the untreated DN, prophylactic, and curative groups when compared with the control group. Treatment with Hyphaene thebaica in the prophylactic and curative groups induced a significant decrease in renal corpuscle diameter compared with the untreated DN group (Table 3, Fig. 4). Non-significant changes were found in terms of urinary space diameter in the studied groups.

The deposition of regular collagen fibres in the mesangial matrix of the glomeruli, the boundaries of Bowman's capsules, and around the basal lamina of the tubules was observed in the control group and the group treated with Hyphaene thebaica only (Fig. 5A). The DN group showed an increase in collagen fibre 
Table 2. Comparison of serum levels of insulin, C-peptide, cystatin C and neutrophil gelatinase-associated lipocalin in different studied groups

\begin{tabular}{|c|c|c|c|c|c|}
\hline Parameters & Control group & Control doum group & DN group & Prophylactic group & Curative group \\
\hline \multirow[t]{5}{*}{ Serum insulin [mlU/L] } & $6.17 \pm 2.16$ & $7.09 \pm 2.69$ & $0.27 \pm 0.13$ & $2.26 \pm 1.66$ & $1.10 \pm 0.91$ \\
\hline & & & ${ }^{1} p<0.0001$ & ${ }^{1} p<0.0001$ & ${ }^{1} p<0.0001$ \\
\hline & & & $2 p<0.0001$ & ${ }^{2} p<0.0001$ & $2 p<0.0001$ \\
\hline & & & & ${ }^{3} p<0.015$ & ${ }^{3} p=0.298$ \\
\hline & & & & & ${ }^{4} p=0.148$ \\
\hline \multirow[t]{5}{*}{ Serum C-peptide [ng/mL] } & $1.16 \pm 0.21$ & $1.26 \pm 0.49$ & $0.24 \pm 0.11$ & $0.72 \pm 0.19$ & $0.44 \pm 0.24$ \\
\hline & & & ${ }^{1} p<0.0001$ & ${ }^{1} p<0.001$ & ${ }^{1} p<0.0001$ \\
\hline & & & ${ }^{2} p<0.0001$ & ${ }^{2} p<0.0001$ & ${ }^{2} p<0.0001$ \\
\hline & & & & ${ }^{3} p<0.0001$ & ${ }^{3} p=0.114$ \\
\hline & & & & & ${ }^{4} p<0.029$ \\
\hline \multirow[t]{5}{*}{ Serum cystatin C [mmol/L] } & $3.42 \pm 0.52$ & $3.78 \pm 0.24$ & $26.5 \pm 0.91$ & $15.12 \pm 0.82$ & $19.24 \pm 0.49$ \\
\hline & & & ${ }^{1} p<0.0001$ & ${ }^{1} p<0.0001$ & ${ }^{1} p<0.0001$ \\
\hline & & & ${ }^{2} p<0.0001$ & ${ }^{2} p<0.0001$ & ${ }^{2} p<0.0001$ \\
\hline & & & & ${ }^{3} p<0.0001$ & ${ }^{3} p<0.0001$ \\
\hline & & & & & ${ }^{4} p<0.0001$ \\
\hline \multirow[t]{5}{*}{ Serum NGAL [ng/mL] } & $0.50 \pm 0.01$ & $0.52 \pm 0.01$ & $1.69 \pm 0.25$ & $1.03 \pm 0.15$ & $1.45 \pm 0.03$ \\
\hline & & & ${ }^{1} p<0.0001$ & ${ }^{1} p<0.0001$ & $1 p<0.0001$ \\
\hline & & & ${ }^{2} p<0.0001$ & ${ }^{2} p<0.0001$ & ${ }^{2} p<0.0001$ \\
\hline & & & & ${ }^{3} p<0.0001$ & ${ }^{3} p<0.0001$ \\
\hline & & & & & ${ }^{4} p<0.006$ \\
\hline
\end{tabular}

Values are presented as mean \pm standard deviation; ${ }^{1} p-$ significance vs. control group; ${ }^{2} p-$ significance vs. control doum group; ${ }^{3} p-$ significance vs. diabetic nephropathy (DN) group; ${ }^{4} \mathrm{p}$ - significance vs. prophylactic group; $\mathrm{N}=10$ for each group

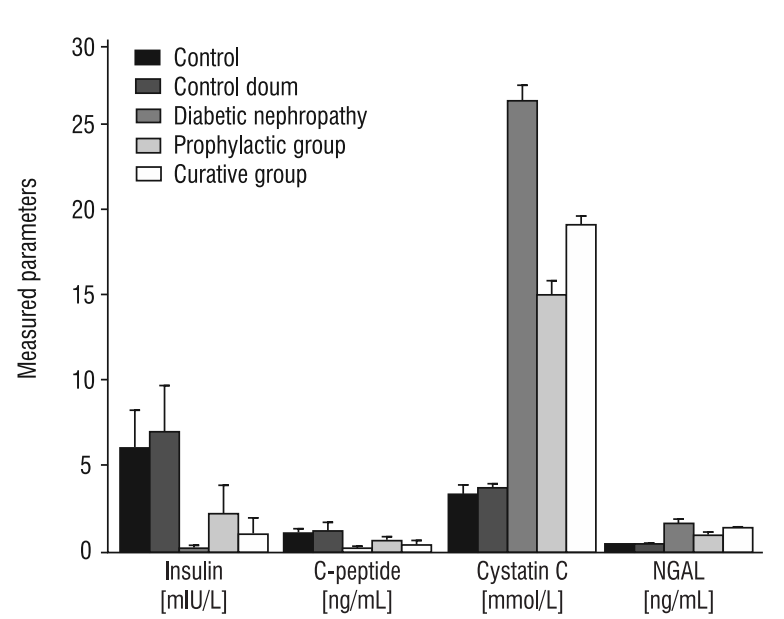

Figure 2. Comparison of serum levels of insulin, C-peptide, cystatin C and neutrophil gelatinase-associated lipocalin (NGAL) in different studied groups.

deposition with seemingly thickened parietal layers in Bowman's capsules and the basal lamina of convoluted tubules, as well as patchy areas of connective tissue around congested dilated blood vessels and vacant areas between certain tubular cells and the basal lamina (Fig. 5B). The group protected from DN by Hyphaene thebaica revealed a slight increase in collagen fibres compared with the control group, yet this increase was still less than that of the diabetic group and included no remarkable changes in terms of glomerular basal lamina thickness or change in the basal lamina of convoluted tubules (Fig. 5C). The DN group treated with Hyphaene thebaica displayed increased collagen deposition in the glomeruli, surrounding Bowman's capsules, and near the convoluted tubules, with both mesangial (global or segmental) and diffuse thickening of the capillary walls (Fig. 5D).

Immunohistochemical results. The negative cytoplasmic staining of the caspase- 3 was noticed in the control group as well as the group treated with Hyphaene thebaica only (Fig. 6A). In the untreated DN group, caspase-3 showed a strong immunoreaction (Fig. 6B). In the group protected from DN 


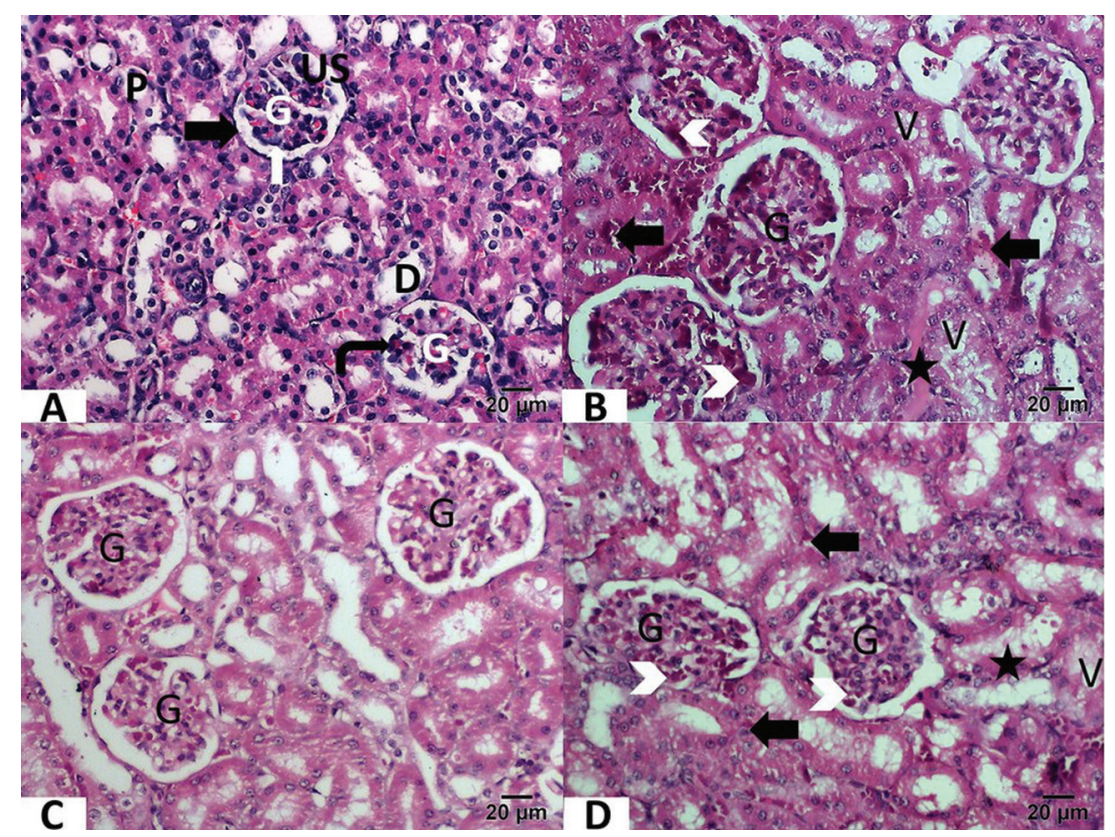

Figure 3. A. Photomicrograph of kidney section of control group showed normal architecture; glomerulus (G), parietal layer (black arrow), visceral layer (white arrow), proximal (P) and distal (D) convoluted tubules, nucleus of podocyte (curved arrow) and urinary space (US); B. Diabetic nephropathy revealed apparently increased size of glomeruli $(G)$ with congested capillary vessels (white arrowhead), vacuolar degeneration of the tubules (V), hyaline casts (star), and areas of extravasated blood cells (black arrow); C. Group protected from diabetic nephropathy showed nearly normal renal architecture; D. Diabetic nephropathy treated with Hyphaene thebaica revealed no observable improvement. Scale bar $20 \mu \mathrm{m}$.

with Hyphaene thebaica, caspase-3 showed a mild immunoreaction (Fig. 6C), while in the diabetic group treated with Hyphaene thebaica, caspase-3 showed moderate to strong expression in terms of an immunoreaction (Fig. 6D).

The immunoexpression of desmin was revealed to be negatively expressed in the control group (Fig. 7A), whereas the untreated DN group showed a strong expression of desmin (Fig. 7B). Lastly, while the group protected from DN demonstrated a mild reaction to desmin (Fig. 7C), the DN-treated group showed moderate to strong desmin expression (Fig. 7D).

A significant elevation in the caspase-3 area percentage and the desmin area percentage was found in the untreated DN, prophylactic, and curative groups compared with the control group. Treatment with Hyphaene thebaica in the prophylactic and curative groups induced a significant decrease in caspase-3 area percentage and desmin area percentage compared with the untreated DN group, yet the formers' levels remained significantly higher than in the control group. Lastly, a significant decrease in caspase-3 area percentage and the desmin area percentage was found in the prophylactic group compared with the curative group (Table 3, Fig. 8).

\section{DISCUSSION}

Hyphaene thebaica contains different flavonoids in its active water-soluble fraction, such as luteolin and chrysoeriol, which help in the improvement of glucose and insulin tolerance. Luteolin inhibits alpha-glucosidase and alpha-amylase, resulting in the decrease of postprandial hyperglycaemia, which reduces rises in blood glucose and significantly decreases blood glycosylated haemoglobin levels [34].

In the present study, glucose levels are increased with a decrease in insulin levels. These results were attributed to the fact that type 2 diabetes mellitus was linked to reduced insulin release or insulin resistance, impaired glucose, lipid metabolisms, as well as activation of oxidative stress indices [4, 31].

The administration of Hyphaene thebaica led to elevated renal function parameters, indicating renal impairments. Wang et al. [45] found similar results with luteolin, one of the active flavonoids found in Hyphaene thebaica, which prevented the development of DN by reducing levels of urea and creatinine $[35,45]$.

Glomerular dysfunction and tubulointerstitial damage are considered essential in the pathogenesis and progression of DN. For these, tubular damage 
Table 3. Mean diameter of renal corpuscle and urinary space by $\mu \mathrm{m}$ and mean area percentage of caspase-3 expression and desmin

\begin{tabular}{|c|c|c|c|c|}
\hline & Control group & DN group & Prophylactic group & Curative group \\
\hline Renal corpuscle diameter $[\mu \mathrm{m}]$ & $83.848 \pm 4.054$ & $85.584 \pm 2.785$ & $82.668 \pm 5.212$ & $82.592 \pm 4.729$ \\
\hline \multirow[t]{3}{*}{$(n=50)$} & & ${ }^{1} p<0.033$ & ${ }^{1} p=0.147$ & ${ }^{1} p=0.123$ \\
\hline & & & ${ }^{2} p<0.0001$ & ${ }^{2} p<0.0001$ \\
\hline & & & & ${ }^{3} p=0.925$ \\
\hline Urinary space diameter $[\mu \mathrm{m}]$ & $7.751 \pm 0.521$ & $7.683 \pm 0.647$ & $7.849 \pm 0.497$ & $7.839 \pm 0.552$ \\
\hline \multirow[t]{3}{*}{$(n=50)$} & & ${ }^{1} p=0.515$ & ${ }^{1} p=0.357$ & ${ }^{1} p=0.407$ \\
\hline & & & ${ }^{2} p=0.117$ & ${ }^{2} p=0.140$ \\
\hline & & & & ${ }^{3} p=0.925$ \\
\hline Caspase-3 area [\%] & $0.562 \pm 0.283$ & $6.542 \pm 0.290$ & $1.015 \pm 0.005$ & $5.531 \pm 0.224$ \\
\hline \multirow[t]{3}{*}{$(n=10)$} & & ${ }^{1} p<0.0001$ & ${ }^{1} p<0.0001$ & ${ }^{1} p<0.0001$ \\
\hline & & & ${ }^{2} p<0.0001$ & ${ }^{2} p<0.0001$ \\
\hline & & & & ${ }^{3} p<0.0001$ \\
\hline Desmin area [\%] & $0.586 \pm 0.081$ & $5.014 \pm 0.714$ & $1.097 \pm 0.229$ & $4.051 \pm 0.739$ \\
\hline \multirow[t]{3}{*}{$(n=10)$} & & ${ }^{1} p<0.0001$ & ${ }^{1} p<0.017$ & ${ }^{1} p<0.0001$ \\
\hline & & & ${ }^{2} p<0.0001$ & ${ }^{2} p<0.0001$ \\
\hline & & & & ${ }^{3} p<0.0001$ \\
\hline
\end{tabular}

Values are presented as mean \pm standard deviation; ${ }^{1} p$ — significance vs. control group; ${ }^{2} p$ - significance vs. diabetic nephropathy (DN) group; ${ }^{3} p$ - significance vs. prophylactic group

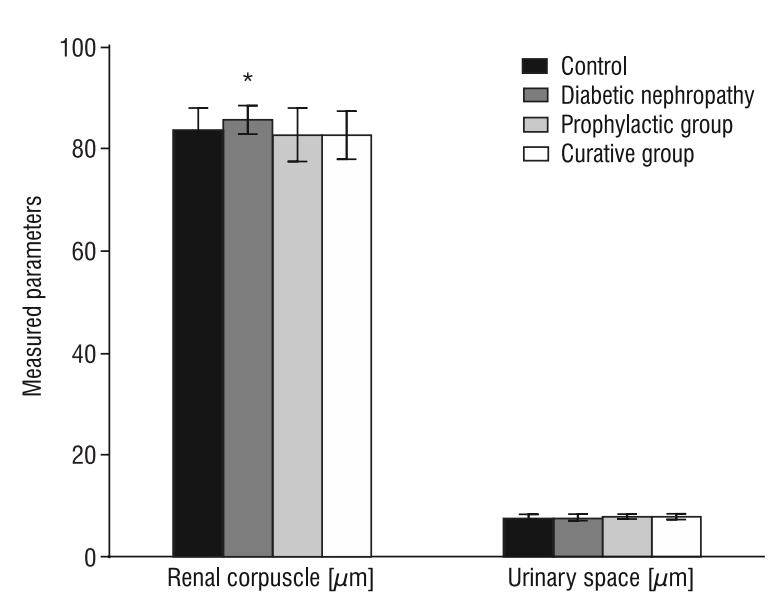

Figure 4. The mean diameter of renal corpuscle and urinary space compared with the control group.

markers, such as serum and urinary Cys $C$ and NGAL, can be used as early predictors of DN [14, 27].

Kim et al. [20] found an increased serum Cys C in patients with DN, which is in accordance with the findings of this study, and Nauta et al. [30] found that DN patients have an increased serum levels of both serum Cys $C$ and NGAL $[5,30]$.

In the current work, serum NGAL levels were found to be significantly elevated in the untreated DN group. These results are in agreement with other researches $[8,38]$. Many studies have concluded that oxidative stress caused by hyperglycaemia enhances diabetic complications, including DN and progress toward end-stage renal disease [12].

In the current study, the administration of Hyphaene thebaica was found to induce a decrease in renal damage biomarkers Cys C and NGAL. This was attributed to the rich amount of flavonoids found in Hyphaene thebaica, which inhibits lipid oxidation by scavenging free radicals or by other mechanisms, such as singlet oxygen quenching, metal chelation, and lipoxygenase inhibition [2]. Hsu et al. [15] have shown that the aqueous extract of Hyphaene thebaica possesses an antioxidant activity due to its substantial amount of water-soluble phenolic content.

In support of the findings of the current study, DN alterations were found to occur at the Bowman's capsule, including thickening of the basal lamina of the parietal layer, glomerular capillaries, and mesangial expansion [13]. The current research found tubular alterations in the untreated DN group in the form of dilatation, vacuolation of the tubular cell lining, and hyaline casts, as well as capillary congestion and apparent fibrosis. All of these results are in accordance with the research of others [19]. These structural changes could be attributed to hyperglycaemia, which might initiate apoptosis due to 


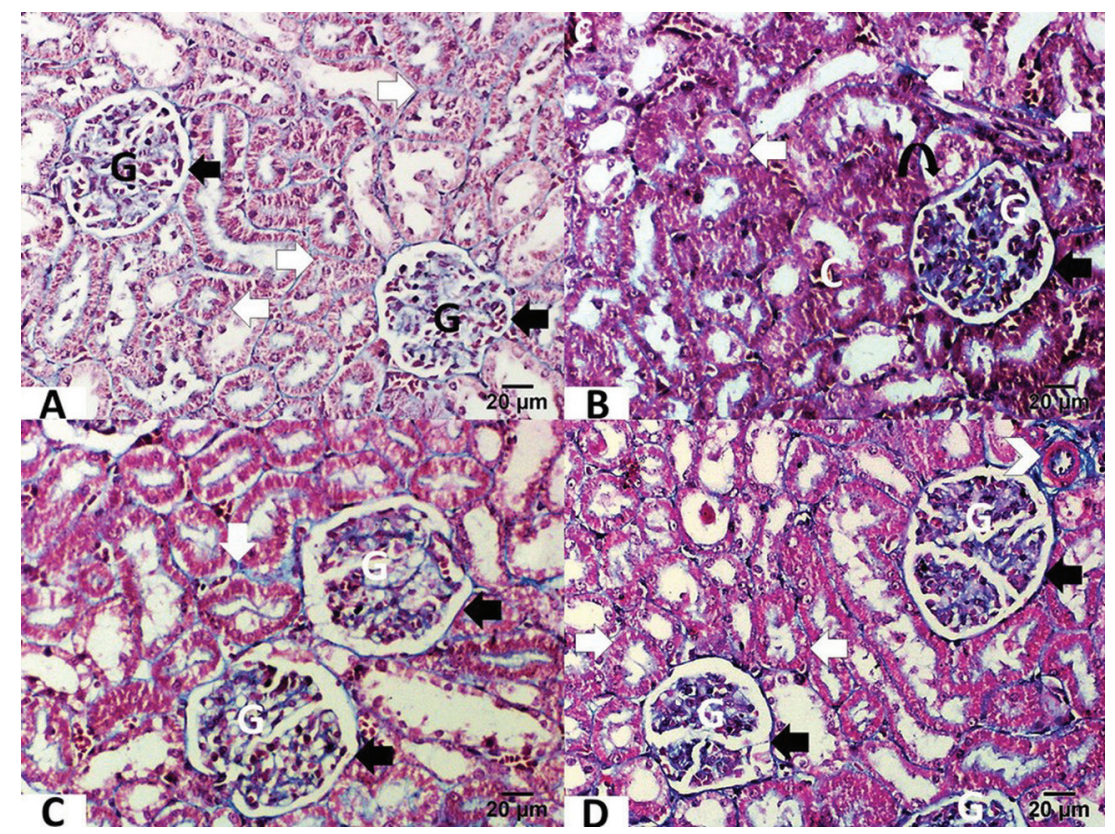

Figure 5. A. Photomicrograph of kidney section of control group showed minimal collagen fibres in the glomeruli (G), Bowman's capsule (black arrow) and around the tubules (white arrow); B. Diabetic nephropathy revealed condensation of collagen fibres in the glomeruli (G), with apparently thickened parietal layer of Bowman's capsule (black arrow), convoluted tubules (white arrows), and congested blood vessels (C) and vacant area between some tubular cells and basal lamina (curved arrow); C. Group protected revealed minimal intraglomerular (G) collagen fibres with no change in the basal lamina thickness (black arrow) and no notable change in convoluted tubules (white arrow); D. Diabetic nephropathy treated showed collagen in the glomeruli (G), surrounding Bowman's capsule (black arrow) and the tubules (white arrow). Note thickening of the capillary walls (white arrowhead). Masson's trichrome, Scale bar $20 \mu \mathrm{m}$.

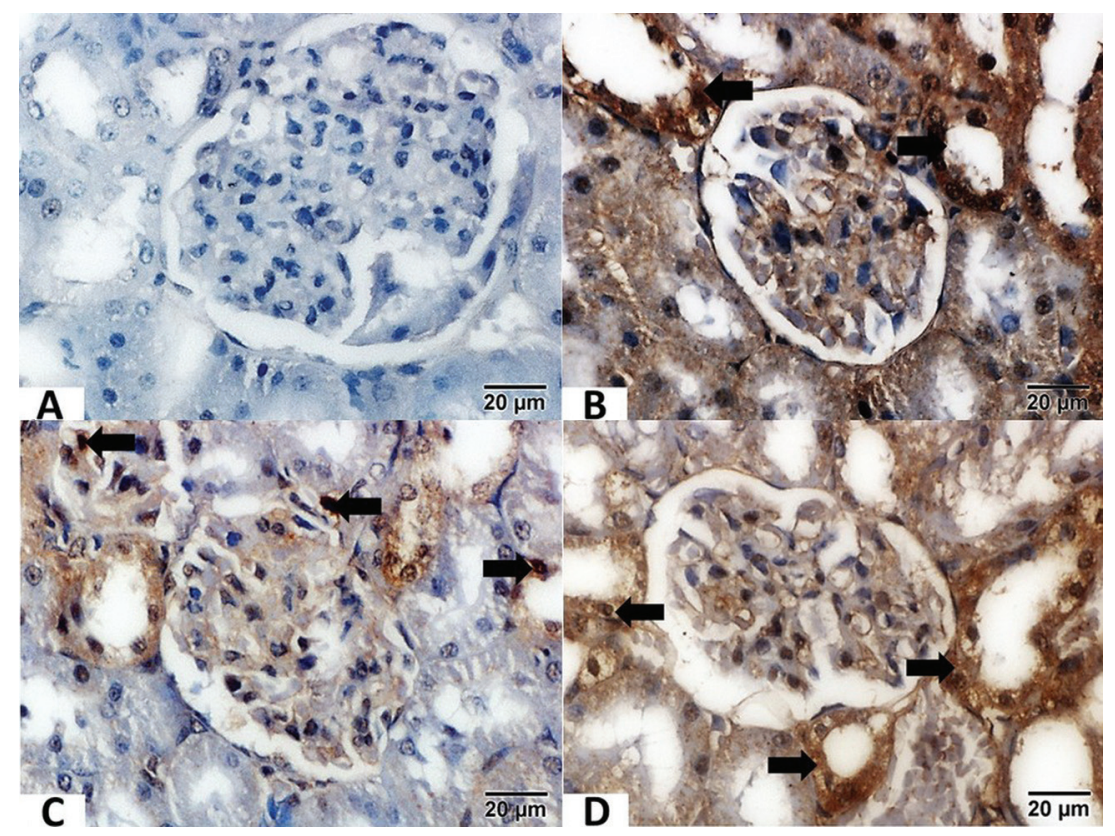

Figure 6. Caspase-3 immunoexpression; A. Control group showed weak immunostaining; B. Diabetic nephropathy group revealed strong caspase-3 expression; C. Mild caspase-3 immunostaining expression in the group protected from diabetic nephropathy; $\mathbf{D}$. Moderate to strong expression of caspase-3 immunostaining (black arrow) in diabetic nephropathy treated group. Scale bar $20 \mu \mathrm{m}$.

mitochondrial dysfunction, increased intracellular $\mathrm{Ca}^{2+}$, and oxidative stress [43]. Obliteration of the capillary lumen observed in a previous research has been associated with mesangial expansion, which leads to the reduction of the renal filtration area, and consequently, glomerular function cessation [33]. 


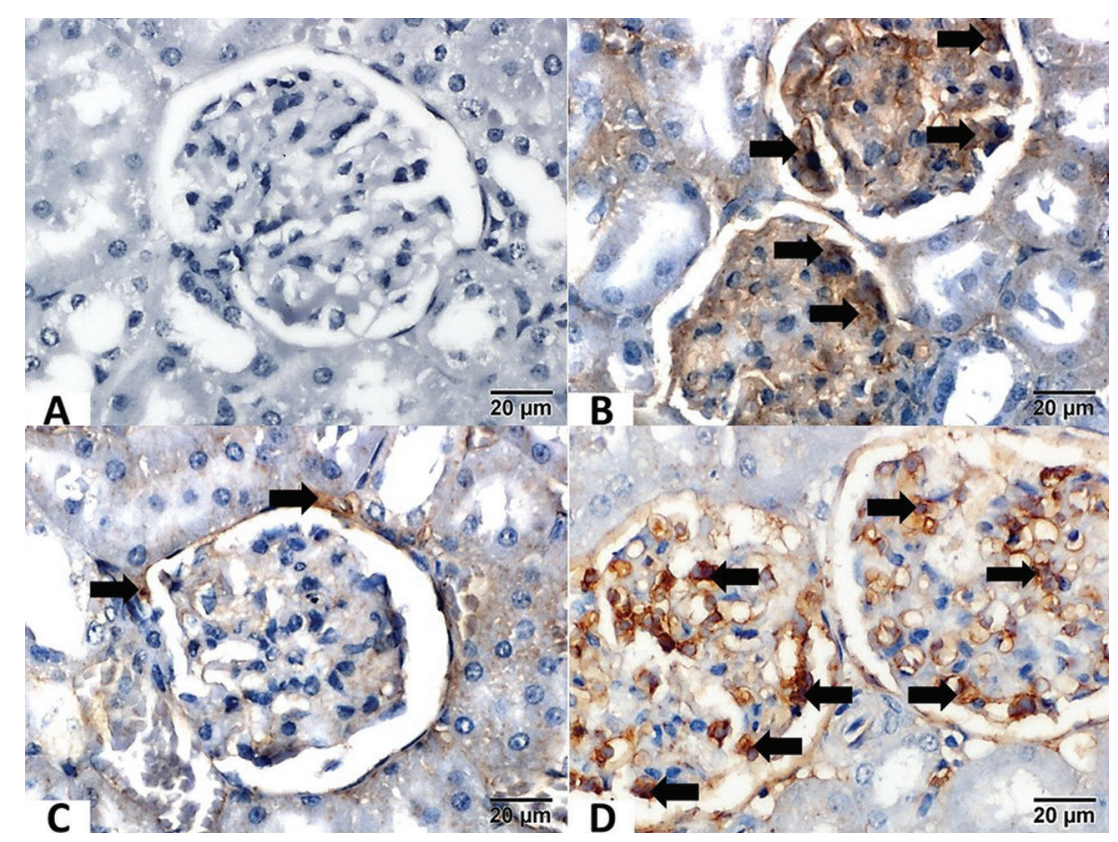

Figure 7. Desmin immunoexpression; A. Control group showed weak immunostaining; B. Diabetic nephropathy group revealed strong desmin expression; C. Mild desmin immune expression in the group protected from diabetic nephropathy; $\mathbf{D}$. Moderate to strong expression of desmin immunostaining (black arrow) in diabetic nephropathy treated group. Scale bar $20 \mu \mathrm{m}$.

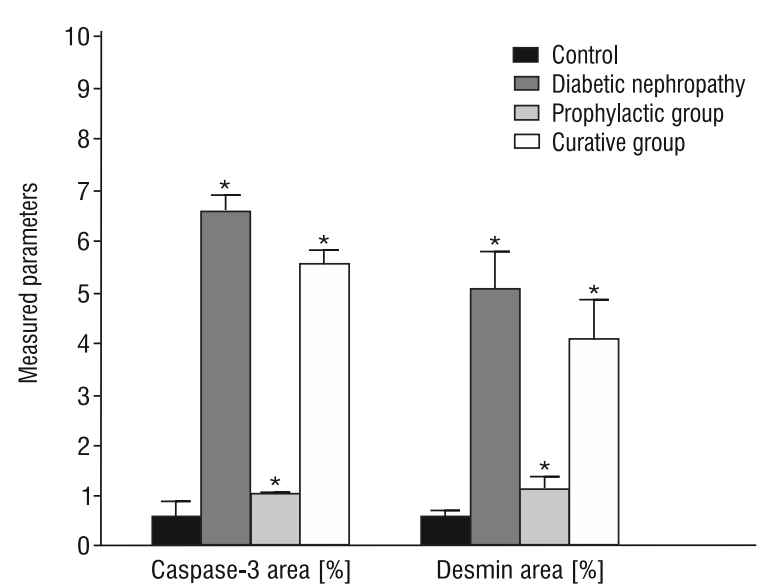

Figure 8. The mean area percentage of caspase-3 expression and desmin compared with the control group.

In the current work, the untreated DN group demonstrated an increased collagen fibre deposition in the mesangial matrix and around the glomerular capillaries. The collagen which came from plasma exudation or was created by mesangial cells [44] might be attributed to hyperglycaemia. Hyperglycaemia leads to increased fibronectin production in response to damage, and fibronectin attracts fibrin, which is essential in cell-collagen interaction and collagen deposition [24].
Caspases are cysteine aspartyl-specific proteases, and caspase- 3 is the main effector caspase in the detection of renal apoptosis and necrotic cell populations $[25,26]$. In the current work, caspase-3 expression was found to be increased in the untreated DN group and significantly diminished by Hyphaene thebaica, especially if used as a protective. The strong expression of caspase- 3 is related to cellular damage or cellular death, which are considered the main reasons for diabetic complications [11]. In accordance with our findings, apoptotic changes have been observed in glomeruli, proximal, and distal convoluted tubular cells [22].

It is well known that podocyte number, density, and proteinuria are closely related [7]. Podocyte injury is always the target of glomerular affection and is involved in the progress of glomerular diseases [10]. In the current work, in accordance with the study by Fioretto and Mauer [13], extensive podocyte damage was detected in Bowman's corpuscles in terms of desmin expression. Increased desmin expression is commonly noticed in many glomerular diseases, especially when podocytes are injured [47]. These injuries can be attributed to the dedifferentiation of the podocyte epithelium accompanied by the initiation of mesenchymal indicators, such as desmin [23]. Podocytes may undergo mesenchymal trans- 
ition and dedifferentiation of the epithelium due to the rise of transforming growth factor beta-1, and therefore the expression of desmin can be considered a trusted applicable indicator for podocyte epithelial and mesenchymal transition [23]. Podocyte injury may be caused by renin-angiotensin-aldosterone and endothelin systems, increased profibrotic cytokines release, elevated protein kinase $\mathrm{C}$, and non-enzymatic glycosylation [9].

\section{CONCLUSIONS}

In conclusion, the results of this study suggest that Hyphaene thebaica can be advised as a protective plant for diabetics to delay the progression of diabetic renal complications.

\section{REFERENCES}

1. Abdel-Rahim EA, El-Beltagi $\mathrm{H}$, Fayed A (2011) Comparative studies on the influences of Juniperus phoenicea and Hyphaena thebaica as hypoglycemic factors in diabetic rats. J Advanc Food Scien, 33: 128-132.

2. Al-Masri SA, Riyadh SA (2012) Effect of doum and methionine combination on hepatotoxicity in rats. Australian J Basic Applied Scien, 6: 392-397.

3. Aremu A, Fadele O (2011) Study of some properties of doum palm fruit (Hyphaene thebaica Mart.) in relation to moisture content. Afr J Agricult Res, 6: 3597-3602.

4. Arumugam S, Sreedhar R, Miyashita S, Karuppagounder V, Thandavarayan RA, Giridharan VV, Pitchaimani V, Afrin R, Harima M, Suzuki K (2014) Comparative evaluation of torasemide and furosemide on rats with streptozotocin-induced diabetic nephropathy. Exp Mol Pathol, 97: 137-143.

5. Assal HS, Tawfeek S, Rasheed EA, El-Lebedy D, Thabet EH (2013) Serum cystatin C and tubular urinary enzymes as biomarkers of renal dysfunction in type 2 diabetes mellitus. Clin Med Insights Endocrinol Diabetes, 6: 7-13.

6. Balakumar P, Chakkarwar VA, Kumar V, Jain A, Reddy J, Singh M (2008) Experimental models for nephropathy. J Renin Angiotensin Aldosterone Syst, 9: 189-195.

7. Benigni A, Gagliardini E, Tomasoni S, Abbate M, Ruggenenti P, Kalluri R, Remuzzi G (2004) Selective impairment of gene expression and assembly of nephrin in human diabetic nephropathy. Kidney Int, 65: 2193-2200.

8. Bolignano D, Lacquaniti A, Coppolino G, Donato V, Fazio MR, Nicocia G, Buemi M (2009) Neutrophil gelatinase-associated lipocalin as an early biomarker of nephropathy in diabetic patients. Kidney Blood Press Res, 32: 91-98.

9. Dronavalli S, Duka I, Bakris GL (2008) The pathogenesis of diabetic nephropathy. Nat Clin Pract Endocrinol Metab, 4: 444-452.

10. El-Aouni C, Herbach N, Blattner SM, Henger A, Rastaldi MP, Jarad G, Miner JH, Moeller MJ, St-Arnaud R, Dedhar S, Holzman LB, Wanke R, Kretzler M (2006) Podocyte-specific deletion of integrin-linked kinase results in severe glomerular basement membrane alterations and progressive glomerulosclerosis. J Am Soc Nephrol, 17: 1334-1344.

11. El-Asrar AMA, Dralands L, Missotten L, Al-Jadaan IA, Geboes K (2004) Expression of apoptosis markers in the retinas of human subjects with diabetes. Invest Ophthalmol Visual Scien, 45: 2760-2766.

12. Elmarakby AA, Sullivan JC (2012) Relationship between oxidative stress and inflammatory cytokines in diabetic nephropathy. Cardiovasc Ther, 30: 49-59.

13. Fioretto P, Mauer M (2007) Histopathology of diabetic nephropathy. Semin Nephrol, 27: 195-207.

14. Flynn ER, Lee J, Hutchens ZM Jr, Chade AR, Maric-Bilkan C (2013) C-peptide preserves the renal microvascular architecture in the streptozotocin-induced diabetic rat. J Diabetes Complications, 27: 538-547.

15. Hsu B, Coupar IM, Ng K (2006) Antioxidant activity of hot water extract from the fruit of the Doum palm, Hyphaene thebaica. Food Chem, 98: 317-328.

16. Hussein AM, Saleh HA, Mustafa HN (2014) Effect of sodium selenite and vitamin $\mathrm{E}$ on the renal cortex in rats: an ultrastructure study. Tissue Cell, 46: 170-177.

17. Inker LA, Schmid CH, Tighiouart $H$, Eckfeldt JH, Feldman HI, Greene T, Kusek JW, Manzi J, Van Lente F, Zhang YL, Coresh J, Levey AS (2012) Estimating glomerular filtration rate from serum creatinine and cystatin C. N Engl J Med, 367: 20-29.

18. Isakova $T$, Xie $H$, Yang $W$, Xie $D$, Anderson AH, Scialla J, Wahl P, Gutiérrez OM, Steigerwalt S, He J, Schwartz S, Lo J, Ojo A, Sondheimer J, Hsu CY, Lash J, Leonard M, Kusek JW, Feldman HI, Wolf M (2011) Fibroblast growth factor 23 and risks of mortality and end-stage renal disease in patients with chronic kidney disease. JAMA, 305: 2432-2439.

19. Kanasaki K, Taduri G, Koya D (2013) Diabetic nephropathy: the role of inflammation in fibroblast activation and kidney fibrosis. Front Endocrinol (Lausanne), 4: 7.

20. Kim EH, Yu JH, Lee SA, Kim EY, Kim WG, Lee SH, Cho EH, Koh EH, Lee WJ, Kim MS, Park JY, Lee KU (2010) Lack of association between serum cystatin $C$ levels and coronary artery disease in diabetic patients. Korean Diabetes J, 34: 95-100.

21. Kim SS, Song SH, Kim IJ, Yang JY, Lee JG, Kwak IS, Kim YK (2012) Clinical implication of urinary tubular markers in the early stage of nephropathy with type 2 diabetic patients. Diabetes Res Clin Pract, 97: 251-257.

22. Kumar D, Zimpelmann J, Robertson S, Burns KD (2004) Tubular and interstitial cell apoptosis in the streptozotocin-diabetic rat kidney. Nephron Experimental Nephrol, 96: e77-e88.

23. Li W, Zheng H, Bukuru J, De Kimpe N (2004) Natural medicines used in the traditional Chinese medical system for therapy of diabetes mellitus. J Ethnopharmacol, 92: 1-21.

24. Li X, Liu W, Wang Q, Liu P, Deng Y, Lan T, Zhang X, Qiu B, Ning $H$, Huang $H$ (2009) Emodin suppresses cell proliferation and fibronectin expression via p38MAPK pathway in rat mesangial cells cultured under high glucose. Mol Cell Endocrinol, 307: 157-162.

25. Liadis N, Murakami K, Eweida M, Elford AR, Sheu L, Gaisano HY, Hakem R, Ohashi PS, Woo M (2005) Caspase-3-dependent beta-cell apoptosis in the initiation of autoimmune diabetes mellitus. Mol Cell Biol, 25: 3620-3629.

26. Menini S, lacobini C, Oddi G, Ricci C, Simonelli P, Fallucca S, Grattarola M, Pugliese F, Pesce C, Pugliese G (2007) Increased glomerular cell (podocyte) apoptosis in rats with streptozotocin-induced diabetes mellitus: role in the development of diabetic glomerular diseass. Diabetologia, 50: 2591-2599. 
27. Moresco RN, Sangoi MB, De Carvalho JA, Tatsch E, Bochi GV (2013) Diabetic nephropathy: traditional to proteomic markers. Clin Chim Acta, 421: 17-30.

28. Mustafa HN, El Awdan SA, Hegazy GA (2013) Protective role of antioxidants on thioacetamide-induced acute hepatic encephalopathy: Biochemical and Ultrastructural study. Tissue Cell, 45: 350-362.

29. Nain P, Saini V, Sharma S, Nain J (2012) Antidiabetic and antioxidant potential of Emblica officinalis Gaertn. leaves extract in streptozotocin-induced type-2 diabetes mellitus (T2DM) rats. J Ethnopharmacol, 142: 65-71.

30. Nauta FL, Boertien WE, Bakker SJ, van Goor H, van Oeveren W, de Jong PE, Bilo H, Gansevoort RT (2011) Glomerular and tubular damage markers are elevated in patients with diabetes. Diabetes Care, 34: 975-981.

31. Nekooeian AA, Eftekhari MH, Adibi S, Rajaeifard A (2014) Effects of pomegranate seed oil on insulin release in rats with type 2 diabetes. Iran J Med Sci, 39: 130-135.

32. Padhy M, Kaushik S, Girish M, Mohapatra S, Shah S, Koner BC (2014) Serum neutrophil gelatinase associated lipocalin (NGAL) and cystatin $C$ as early predictors of contrast-induced acute kidney injury in patients undergoing percutaneous coronary intervention. Clin Chim Acta, 435: 48-52.

33. Quezada C, Alarcon S, Jaramillo C, Munoz D, Oyarzun C, San Martin R (2013) Targeting adenosine signaling to treatment of diabetic nephropathy. Curr Drug Targets, 14: 490-496.

34. Salib JY, Michael HN, Eskande EF (2013) Anti-diabetic properties of flavonoid compounds isolated from Hyphaene thebaica epicarp on alloxan induced diabetic rats. Pharmacognosy Res, 5: 22-29.

35. Saravanan G, Leelavinothan P (2012) Effects of Syzygium cumini bark on blood glucose, plasma insulin and C-peptide in streptozotocin induced diabetic rats. Int J Endocrinol Metab, 4: 96-105.

36. Shaker OG, El-Shehaby A, El-Khatib M (2010) Early diagnostic markers for contrast nephropathy in patients undergoing coronary angiography. Angiology, 61: 731-736.

37. Shehu B, Gidado A, Buratai L (2014) Hypoglycaemic, hypolipidaemic and possible toxicity of the methanolic fruit pulp extract of hyphane thebaica (L) Mart in alloxan-induced diabetic rats. J Med Applied Bioscien, 6: 1-10.

38. Simsek A, Tugcu V, Tasci Al (2013) New biomarkers for the quick detection of acute kidney injury. ISRN Nephrol, 2013: 394582

39. Sirota JC, Walcher A, Faubel S, Jani A, McFann K, Devarajan P, Davis CL, Edelstein CL (2013) Urine IL-18, NGAL, IL-8 and serum IL-8 are biomarkers of acute kidney injury following liver transplantation. BMC Nephrol, 14: 17.

40. Soler MJ, Riera M, Batlle D (2012) New experimental models of diabetic nephropathy in mice models of type 2 diabetes: efforts to replicate human nephropathy. Exp Diabetes Res, 2012: 616313.

41. Suvarna KS, Suvarna SK, Layton C, Bancroft JD (2012) Bancroft's Theory and practice of histological techniques, expert consult: Online and Print, 7: Elsevier Health Sciences, pp. 105-123.

42. Tramonti G, Kanwar YS (2013) Review and discussion of tubular biomarkers in the diagnosis and management of diabetic nephropathy. Endocrine, 43: 494-503.

43. Van den Oever IA, Raterman HG, Nurmohamed MT, Simsek S (2010) Endothelial dysfunction, inflammation, and apoptosis in diabetes mellitus. Mediators Inflamm, 2010: 792393.

44. Venkatesh S, Madhava Reddy B, Dayanand Reddy G, Mullangi R, Lakshman M (2010) Antihyperglycemic and hypolipidemic effects of Helicteres isora roots in alloxan-induced diabetic rats: a possible mechanism of action. J Nat Med, 64: 295-304.

45. Wang GG, Lu XH, Li W, Zhao X, Zhang C (2011) Protective effects of luteolin on diabetic nephropathy in STZ-induced diabetic rats. Evid Based Complement Alternat Med, 2011: 323171

46. Zheng $H$, Whitman SA, Wu W, Wondrak GT, Wong PK, Fang D, Zhang DD (2011) Therapeutic potential of Nrf2 activators in streptozotocin-induced diabetic nephropathy. Diabetes, 60: 3055-3066.

47. Zou J, Yaoita E, Watanabe Y, Yoshida Y, Nameta M, Li H, Qu Z, Yamamoto T (2006) Upregulation of nestin, vimentin, and desmin in rat podocytes in response to injury. Virchows Arch, 448: 485-492. 